\title{
A MODIFIED ANP AND ITS APPLICATION IN SIMULATION CREDIBILITY EVALUATION
}

\author{
Shi, P.; Liu, F. \& Yang, M. \\ Control and Simulation Centre, Harbin Institute of Technology, China \\ E-Mail: shinkhit@yahoo.cn
}

\begin{abstract}
With the size and complexity of simulation applications growing rapidly, many simulation systems cannot be structured hierarchically, involving the interaction and dependence of elements in a hierarchy. To give an efficient credibility evaluation for the intricate simulation systems involving network configuration, this paper proposes a modified fuzzy ANP method to calculate weights of indices for assessing. The method used triangle fuzzy numbers to establish judgment matrix, together with confidence level, expressing Subject Matter Experts' degree of understanding with respect to the importance of each component. Furthermore, a new possibility measurement for fuzzy numbers is proposed, to obtain the relative importance ranking of components for the simplified judgment in dealing with the vagueness defined measurement scales. The approach is used to calculate the credibility of a control and guide simulation system for a type of missile. The application result shows that the method is reasonable, easy and feasible.

(Received in January 2010, accepted in October 2010. This paper was with the authors 1 month for 1 revision.)
\end{abstract}

Key Words: ANP, Triangle Fuzzy Numbers, Confidence Level, Credibility Evaluation, Simulation System

\section{INTRODUCTION}

The Analytic Network Process (ANP) generalizes a widely used multi-criteria decision making tool, the Analytic Hierarchy Process (AHP), by replacing hierarchies with networks $[1,2]$. The AHP works by developing priorities for alternatives and the criteria used to judge the alternatives. Priorities are derived for the criteria in terms of their importance to achieve the goal, and then priorities are derived for the performance of the alternatives on each criterion. These priorities are derived based on pairwise assessments using judgment, or ratios of measurements from a scale if one exists. Finally, a weighting and adding process is used to obtain overall priorities for the alternatives as to how they contribute to the goal. With the AHP a multidimensional scaling problem is thus transformed to a uni-dimensional scaling problem. However, in many cases, there is interdependence among criteria and alternatives. The ANP can be used as an effective tool in those cases where the interactions among the elements of a system form a network structure. ANP uses ratio scale measurements based on pairwise comparisons; however, it does not impose a strict hierarchical structure as in AHP, and models a decision problem using a systems-with-feedback approach. The ANP feedback approach replaces hierarchies with networks in which the relationships between levels are not easily represented as higher or lower, direct or indirect. For instance, not only does the importance of the criteria determine the importance of the alternatives, as in a hierarchy, but also the importance of the alternatives may have impact on the importance of the criteria [3, 4]. Therefore, a hierarchical structure with a linear top-to-bottom form is not suitable for a complex system.

A modified fuzzy ANP method to calculate weights of indices for assessing the credibility of simulation system is proposed. The framework integrates Subject Matter Experts' degree of 
understanding, a new possibility fuzzy numbers measurement for weight vectors, and relative importance ranking in dealing with the vagueness of poorly defined measurement scales. The method is more flexible and accurate than traditional methods in simulation credibility evaluation.

The remainder of this paper is organized as follows: Section 2 gives the literature survey, and the limitations of the existing methods. Section 3 argues the modified fuzzy ANP process in detail. From the analytic results of this integrated model, a relative importance ranking for each evaluation component is obtained. Section 4 presents the V\&V evaluation system based on hierarchical and network evaluation as the groundwork for further network analysis. An empirical illustration of the control and guide simulation system for a type of missile is given in Section 5. Concluding remarks and further researches are presented in Section 6.

\section{RELATED WORKS}

The perceptions and judgments of human are represented by linguistic and vague patterns for a complex problem, especially in credibility studies of simulation systems. That also challenges both the conventional AHP and ANP, in which the pairwise comparisons for each level with respect to the goal of the best alternative selection are conducted using a nine-point scale. The application of Saaty's ANP has some shortcomings as follows: (1) Identifying the relevant attributes of the problem and determining their relative importance in decision-making process requires extensive discussion and brainstorming sessions. Also, data acquisition is a very time intensive process for ANP methodology. (2) The pair-wise comparison of attributes under consideration can only be subjectively performed, and hence their accuracy of the results depends on the user's expertise knowledge in the area concerned. (3) The ANP method does not take into account the uncertainty associated with the mapping of one's judgment to a number. (4) Ranking of the ANP method is rather imprecise. (5) ANP requires more calculations and formation of additional pair-wise comparison matrices as compared to the AHP process. Thus, a careful track of matrices and pairwise comparisons of attributes is necessary.

To overcome these problems, several researchers integrate fuzzy theory with AHP to improve the uncertainty. The earliest research in fuzzy AHP appeared in van Laarhoven and Pedrycz [5], which compared fuzzy ratios described by triangular membership functions and the logarithmic least squares method to obtain element sequencing. Buckley [6] determined fuzzy priorities of comparison ratios whose membership functions were trapezoidal. Chang [7, 8] introduced an approach with the use of triangular fuzzy numbers for pairwise comparison scale of fuzzy AHP. Chen [9] proposed modified method using simplified fuzzy number arithmetic operations rather than the complicated entropy weight calculations. Chen and Cheng [10] proposed an algorithm for evaluating naval tactical missile systems by the fuzzy AHP method and entropy concepts to calculate aggregate weights. These aforementioned studies calculate fuzzy priorities based on arithmetic operations for fuzzy triangular or trapezoidal numbers. Yang [11] proposed the fuzzy AHP based on the fuzzy interval arithmetic and confidence level $\alpha$ with interval mean approach to determine the weights for evaluative elements for key quality-performance evaluation. Ayag [12] also proposed the fuzzy AHP based on the fuzzy interval arithmetic and confidence level for multiple criteria decision making (MCDM) problem. Saaty [2-4] modified his AHP/ANP studies on adding utility theory, and time factors in his latest researches. Table I gives the comparison of various modified fuzzy methods.

As the process of ANP is similar with AHP, some improvements on AHP could be used to modify the ANP approach. 
Table I: Comparison of various modified fuzzy methods.

\begin{tabular}{|c|c|c|}
\hline Authors & Key characteristics & Advantages (A) / Disadvantages (D) \\
\hline \multirow{2}{*}{$\begin{array}{l}\text { Van } \\
\text { Laarhoven \& } \\
\text { Pedrycz } \\
\text { (1983) }\end{array}$} & \multirow{2}{*}{$\begin{array}{l}\text { Direct extension of } \\
\text { Saaty’s AHP method } \\
\text { with triangular fuzzy } \\
\text { numbers. }\end{array}$} & $\begin{array}{l}\text { (A) The opinions of multiple decision-makers can } \\
\text { be modeled in the reciprocal matrix. }\end{array}$ \\
\hline & & $\begin{array}{l}\text { (D) There is not always a solution to the linear } \\
\text { equations. }\end{array}$ \\
\hline \multirow[t]{2}{*}{$\begin{array}{l}\text { Buckley } \\
(1985)\end{array}$} & \multirow{2}{*}{$\begin{array}{l}\text { Direct extension of } \\
\text { Saaty’s AHP method } \\
\text { with trapezoidal fuzzy } \\
\text { numbers. }\end{array}$} & $\begin{array}{l}\text { (A) It guarantees a unique solution to the reciprocal } \\
\text { comparison matrix. }\end{array}$ \\
\hline & & (D) The computational requirement is tremendous. \\
\hline \multirow[t]{2}{*}{$\begin{array}{l}\text { Chang (1996, } \\
\text { 1999) }\end{array}$} & \multirow{2}{*}{$\begin{array}{l}\text { Triangular fuzzy } \\
\text { numbers for pairwise } \\
\text { comparison scale of } \\
\text { fuzzy AHP. }\end{array}$} & $\begin{array}{l}\text { (A) The computational requirement is relatively } \\
\text { low. }\end{array}$ \\
\hline & & $\begin{array}{l}\text { (D) Only calculate the left end points, center points } \\
\text { and, right end points, and these points were only } \\
\text { rude approximate to the judgments. }\end{array}$ \\
\hline \multirow[t]{2}{*}{$\begin{array}{l}\text { Chen (1996, } \\
\text { 2005) }\end{array}$} & \multirow{2}{*}{$\begin{array}{l}\text { Entropy concepts to } \\
\text { calculate aggregate } \\
\text { weights. }\end{array}$} & $\begin{array}{l}\text { (A) The computational requirement is not } \\
\text { tremendous. }\end{array}$ \\
\hline & & $\begin{array}{l}\text { (D) Entropy is used when probability distribution is } \\
\text { known. The method is based on both probability } \\
\text { and possibility measures. }\end{array}$ \\
\hline \multirow[t]{2}{*}{ Yang (2004) } & \multirow{2}{*}{$\begin{array}{l}\text { Fuzzy AHP based on the } \\
\text { fuzzy interval arithmetic } \\
\text { and confidence levels } \\
\text { with interval mean } \\
\text { approach. }\end{array}$} & $\begin{array}{l}\text { (A) Confidence interval and geometric mean } \\
\text { approach express the degree of understanding with } \\
\text { respect to the attributes of criteria. }\end{array}$ \\
\hline & & $\begin{array}{l}\text { (D) Neglected the center points, which were the } \\
\text { important information for fuzzy numbers. }\end{array}$ \\
\hline \multirow[t]{2}{*}{ Ayag (2006) } & \multirow{2}{*}{$\begin{array}{l}\text { Fuzzy logic and } \\
\text { triangular fuzzy numbers, } \\
\text { with the index of } \\
\text { optimism and confidence } \\
\text { level. }\end{array}$} & $\begin{array}{l}\text { (A) The index of optimism and confidence level } \\
\text { expresses the degree of understanding. }\end{array}$ \\
\hline & & $\begin{array}{l}\text { (D) Neglected the center points, which were the } \\
\text { important information especially for triangular } \\
\text { fuzzy numbers. }\end{array}$ \\
\hline \multirow[t]{2}{*}{$\begin{array}{l}\text { Saaty (2004, } \\
2005,2007)\end{array}$} & \multirow[t]{2}{*}{$\begin{array}{l}\text { Utility theory, group } \\
\text { judgment, and time } \\
\text { factors for dynamic } \\
\text { comparisons }\end{array}$} & $\begin{array}{l}\text { (A) Utility theory, group judgment and time factors } \\
\text { would make a good decision requires judgments of } \\
\text { what is more likely or more preferred over } \\
\text { different time periods and groups }\end{array}$ \\
\hline & & $\begin{array}{l}\text { (D) Ignore the uncertainty in the comparisons for } \\
\text { judgment }\end{array}$ \\
\hline
\end{tabular}

There are many studies in the literature using ANP to solve different problems on several fields. Dagdeviren [13] developed a fuzzy ANP approach to make better decisions in work system safety process and strategic energy policies. Guneri [14] used ANP to get best alternative in shipyard location selection. Fiala [15] proposed a Dynamic Network Process (DNP) to analyses the problems in global relationships network economy among today's economic subjects characterized by massive connectivity. Diederik [16] proposed a benefits opportunities costs risks (BOCR) analysis using AHP/ANP methodology. Chung [17] gave an application of ANP for the selection of product mix for efficient manufacturing in a semiconductor fabricator. Agarwal [18] used ANP for supply chain management. Yuksel [19] used ANP in a SWOT analysis.

Above all, conventional ANP studies prone to use crisp pairwise comparison, which may ignore the vagueness and uncertainty existing in the credibility evaluation judgment. Although some research introduce fuzzy number to describe the uncertainty, these still could 
not give a sufficiency depiction of confidence level, expressing SME's degree of understanding in pairwise comparisons.

\section{MODIFIED FUZZY ANP}

In this paper, a fuzzy ANP approach is proposed to make up the vagueness and uncertainty existing in the credibility evaluation judgment, because the crisp pairwise comparison in the conventional ANP seems to insufficient and imprecise to capture the degree of importance of decision-maker(s) on evaluating indices. What's more, triangular fuzzy numbers were introduced into the conventional ANP in order to improve the degree of judgments of decision-maker(s). The central value of a fuzzy number is the corresponding real crisp number. Then we propose a modified fuzzy ANP (MFANP) approach based on triangular fuzzy numbers under the confidence level $\alpha$, indicating experts' degree of understanding with respect to the importance of each component, and furthermore calculate the possibility of fuzzy numbers to determine the weights vectors for evaluative elements. Finally, aggregating the judgment matrices to the fuzzy ANP means that an overall weighted ranking value reflecting the components' relative importance can be obtained.

The framework of this method is shown in Fig. 1. This framework is divided into three parts: (1) the construction of a hierarchical structure; (2) MFANP implementation; and (3) the establishment of priority relative importance vector and credibility results. From the analytic results of this integrated model, a relative importance ranking for each evaluation hierarchy is obtained. Moreover, the importance priority can enable a prediction of a suitable management decision on the evaluation of few vital components. In the following subsections, an explanation of the method is given in details, involving analytic network structure, fuzzy number calculation with confidence level, and weights obtain.

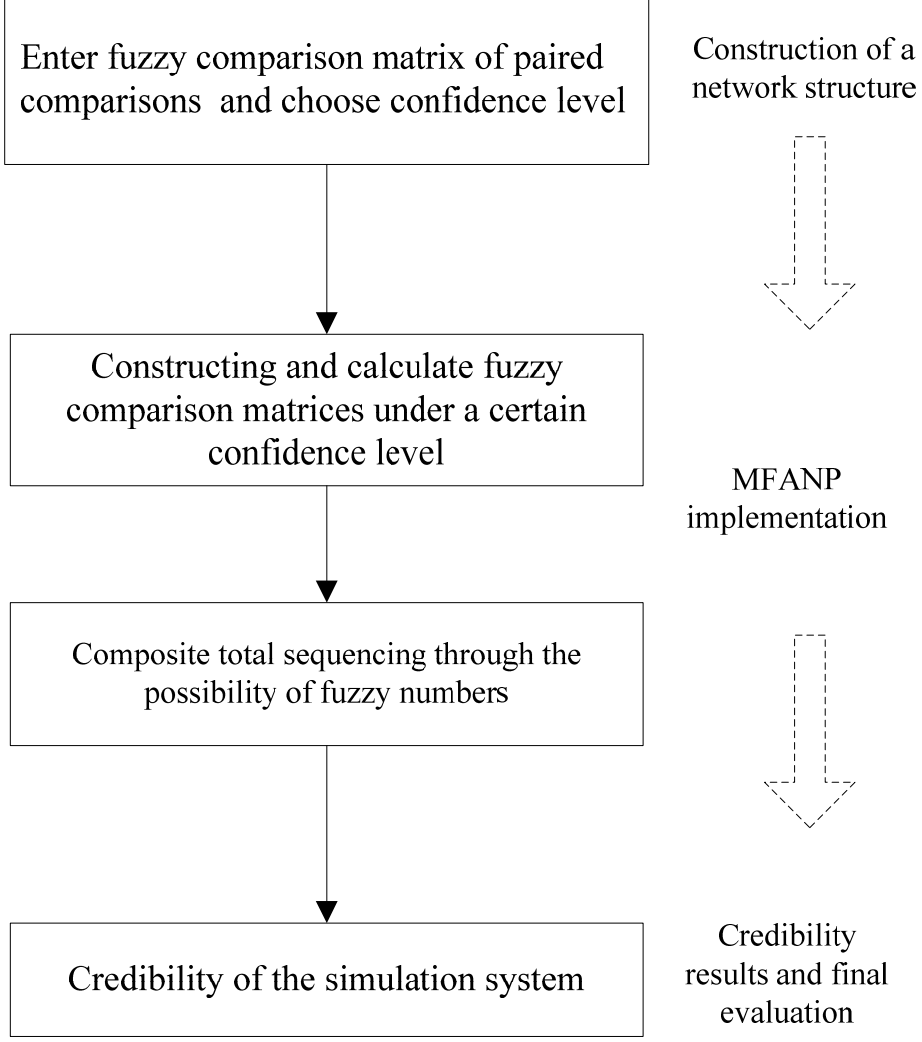

Figure 1: The framework of MFANP approach. 


\subsection{Analytic network structure}

The network structure for the application has been formed via specially application purpose after extensive discussion and brainstorming sessions with Subject Matter Experts (SMEs). What's more, the network structure and the unified evaluation indices should be accepted by all the evaluators as the fundamental to further modified fuzzy ANP process.

\subsection{Weights studies}

After established the network of system credibility, we perform the pairwise comparison of ANP. The decision-maker(s) is asked to compare the elements at a given level on a pairwise basis to estimate their relative importance in relation to the element at the immediate proceeding level. In conventional ANP, the pairwise comparison is made by using a ratio scale. A frequently used scale is the nine-point scale [2] which shows the participants' judgments or preferences among the options such as equally important, weakly more important, strongly more important, very strongly more important, and extremely more important preferred. Even though the discrete scale of 1-9 has the advantages of simplicity and easiness for use, it does not take into account the uncertainty associated with the mapping of one's perception or judgment to a number.

In this section, basic definitions and signals of the fuzzy set theory are provided first.

A fuzzy number is a fuzzy set on real numbers. It represents information such as "about $m "$. A fuzzy number must have a unique modal value $m$, be convex, and piecewise continuous. This definition is generally too broad for direct implementation. A common approach is to limit the shape of the membership functions as defined by LR parameter fuzzy numbers. Triangular fuzzy numbers (TFNs) are a special case of LR parameter fuzzy numbers. A TFN $\tilde{A}$ is completely represented by a triplet such as $\left(a_{l}, a_{m}, a_{u}\right)$ whose membership function $\mu_{\tilde{A}}(x)$ is defined as:

$$
\mu_{\tilde{A}}(x)=\left\{\begin{array}{cc}
\frac{x-a_{l}}{a_{m}-a_{l}} & a_{l} \leq x<a_{m} \\
\frac{a_{u}-x}{a_{u}-a_{m}} & a_{m} \leq x \leq a_{u} \\
0 & \text { others }
\end{array}\right.
$$

Specially, let $a_{l}<a_{m}=a_{u}$, then:

$$
\mu_{\tilde{A}}(x)=\left\{\begin{array}{cc}
\frac{x-a_{l}}{a_{m}-a_{l}} & a_{l} \leq x \leq a_{m}=a_{u} \\
0 & \text { others }
\end{array}\right.
$$

Let $a_{l}=a_{m}=a_{u}$, then:

$$
\mu_{\tilde{\AA}}(x)=\left\{\begin{array}{cc}
1 & x=a_{l}=a_{m}=a_{u} \\
0 & \text { others }
\end{array}\right.
$$

Let $a_{l}=a_{m}<a_{u}$, then:

$$
\mu_{\tilde{A}}(x)=\left\{\begin{array}{cc}
\frac{a_{u}-x}{a_{u}-a_{m}} & a_{l}=a_{m}<x \leq a_{u} \\
0 & \text { others }
\end{array}\right.
$$

Using the interval of confidence at a given level $\alpha$, the triangular fuzzy number has the following characteristics:

$$
A^{\alpha}=\left[a_{l}^{\alpha}, a_{m}, a_{u}^{\alpha}\right]=\left[\left(a_{m}-a_{l}\right) \alpha+a_{l}, a_{m},-\left(a_{u}-a_{m}\right) \alpha+a_{u}\right] \forall \alpha \in[0,1]
$$


For example, $A^{\alpha}=3^{\alpha}=[1,3,5]^{\alpha}=[1+2 \alpha, 3,5-2 \alpha], 3_{\alpha}^{-1}=\left([1,3,5]^{\alpha}\right)^{-1}=\left[\frac{1}{5-2 \alpha}, \frac{1}{3}, \frac{1}{1+2 \alpha}\right]$;

$$
A^{\alpha}=3^{\alpha}=[2,3,4]^{\alpha}=[2+\alpha, 3,4-\alpha], \quad 3_{\alpha}^{-1}=\left([2,3,4]^{\alpha}\right)^{-1}=\left[\frac{1}{4-\alpha}, \frac{1}{3}, \frac{1}{2+\alpha}\right] .
$$

The arithmetic of triangular fuzzy numbers depends on the interval of confidence level $\alpha$. Some basic algebraic operations on the positive triangular fuzzy numbers $\tilde{A}$ and $\tilde{B}$ represented by the interval of confidence are as follows:

$$
\begin{aligned}
& \tilde{A}^{\alpha}+\tilde{B}^{\alpha}=\left[a_{l}^{\alpha}+b_{l}^{\alpha}, a_{m}+b_{m}, a_{u}^{\alpha}+b_{u}^{\alpha}\right] \\
& \tilde{A}^{\alpha}-\tilde{B}^{\alpha}=\left[a_{l}^{\alpha}-b_{u}^{\alpha}, a_{m}-b_{m}, a_{u}^{\alpha}-b_{l}^{\alpha}\right] \\
& \tilde{A}^{\alpha} \times \tilde{B}^{\alpha}=\left[a_{l}^{\alpha} b_{l}^{\alpha}, a_{m} b_{m}, a_{u}^{\alpha} b_{u}^{\alpha}\right] \\
& \tilde{A}^{\alpha} \div \tilde{B}^{\alpha}=\left[a_{l}^{\alpha} / b_{u}^{\alpha}, a_{m} / b_{m}, a_{u}^{\alpha} / b_{l}^{\alpha}\right]
\end{aligned}
$$

After the definitions and signals of basic fuzzy set theory, we give the algorithm of ANP to calculate the fuzzy numbers and the layer of simple sequencing, and further the weight vectors.

The triangular fuzzy numbers are utilized at various $\alpha$ levels to represent the fuzzy numbers in all modules and components judgment matrices. The synthetic triangular fuzzy number of the $k^{\text {th }}$ layer can be derived and the synthetic judgment matrix of the $k^{\text {th }}$ layer total factors towards the $h^{\text {th }}$ factor of the $(k-1)^{\text {th }}$ layer can also be obtained. From the formula:

$$
S_{j}^{k}=\sum_{j=1}^{n} A_{i j}^{k} \times\left(\sum_{i=1}^{n_{k}} \sum_{j=1}^{n_{k}} A_{i j}^{k}\right)^{-1} \quad i=1,2, \cdots n_{k}
$$

In order to rank fuzzy numbers, first we take these fuzzy numbers as triangular fuzzy numbers approximately, and then calculate the possibility of fuzzy number $\tilde{A}>\tilde{B}$ as follows:

$$
P(\tilde{A} \geq \tilde{B})=\frac{\min \left\{a_{u}-a_{l}+b_{u}-b_{l}+\left|b_{m}-a_{m}\right|, \max \left\{a_{u}-b_{l}+\max \left\{a_{m}-b_{m}, 0\right\}, 0\right\}\right\}}{a_{u}-a_{l}+b_{u}-b_{l}+\left|b_{m}-a_{m}\right|}
$$

Theorem 1. Let $\tilde{A}$ and $\tilde{B}$ be positive triangular fuzzy numbers, then:

(a) $0 \leq P(\tilde{A} \geq \tilde{B}) \leq 1$;

(b) If $b_{u} \leq a_{l}$, then $P(\tilde{A} \geq \tilde{B})=1$;

(c) If $a_{u} \leq b_{l}$, then $P(\tilde{A} \geq \tilde{B})=0$;

(d) $P(\tilde{A} \geq \tilde{A})=\frac{1}{2}$;

(e) $P(\tilde{A}>\tilde{B})+P(\tilde{B} \geq \tilde{A})=1$.

The proposed possibility approach of fuzzy numbers is much better than the methods of Chang [5, 6], Ayag [10] and Yang [9], which only concern part of the fuzzy values. In Chang's method, the central values were mainly concerned, if $a_{m} \geq b_{m}$, then $P(\tilde{A}>\tilde{B})=1$, and if $a_{m} \leq b_{m}$, then a value $P(\tilde{A}>\tilde{B}) \in(0,1)$ for the later sequencing of weight vectors. So that's illogicality. If $a_{m} \neq b_{m}$ and $a_{l}=b_{l}, a_{u}=b_{u}$, then we get $\tilde{A}=\tilde{B}$ through both Ayag and Yang's methods, that's also inconsistency.

Theorem 2. Let $\tilde{A}_{i} \quad(i=1,2, \cdots, n)$ be positive triangular fuzzy numbers, then:

$$
P\left(A_{i} \geq A_{1}, A_{2}, \cdots, A_{n}\right)=\frac{1}{n} \sum_{j=1}^{n} P\left(A_{i} \geq A_{j}\right)
$$


Hence, the probabilities of preference an object is found. The combination of probabilities introduces the weight vector. The normalized version of weight vectors are the values we are going to use when choosing alternatives. After ranking fuzzy numbers through the possibility comparison, we could get the normalized weight vectors via normalization.

After all comparisons and weighing processes are done, we obtain super matrix. Cluster weights are implicated to this matrix then weighed super matrix is obtained. When weighed super matrix is ready, powers of this matrix must be calculated and when consecutive powers are the same, then, the power calculating process is over. This last matrix is the limit super matrix. To normalize every column in the limit super matrix, last priorities in terms of alternatives are introduced and the alternative which has the top value is chosen as the best alternative. If all columns have the same value, it is not an incorrect result. On the contrary, it shows that we have found the correct limit matrix. When analyze any column, we can see the real weights in the network.

\section{V\&V SYSTEMS BASED ON NETWORK EVLUATION}

The importance of computer simulations in the design and performance assessment of engineering systems has increased dramatically during the last three or four decades [20, 21]. Verification and validation $(\mathrm{V} \& \mathrm{~V})$ [22] are the primary processes for quantifying and building credibility in numerical models. V\&V methods and procedures have fundamentally improved the credibility of simulations in several high consequence application military areas. But a complex simulation system is exploited by many development agents and developers who concern about different things, introducing more difficulties in credibility evaluation. Most researches on the credibility evaluation of simulation systems involved credibility indices under an evaluation framework [23-25], for network simulation framework would make the credibility studies easily and clearly according to the characteristics of the simulation models.

We introduce a $V \& V$ evaluation system to try to resolve the evaluation problem based on the description of $\mathrm{V} \& \mathrm{~V}$ network. It uses a combination of evaluation processes and indexes which are decomposed according to the $V \& V$ network. Then comes the network evaluation mechanism based on evaluator weight and evaluation network, and finally a comprehensive evaluation system is established.

Before evaluation, the $\mathrm{V} \& \mathrm{~V}$ evaluation principal must establish the evaluation network with the cooperation of evaluators, and ensure all evaluators have accepted the network and the unified evaluation indices as the fundamental to further modified fuzzy ANP process. The evaluation network is an upside-down tree1ike structure composed of evaluation nodes, as shown in Fig. 2. There is a root node at the top, branch nodes in the middle, and many leaf nodes at the bottom. The evaluation at one node only considers its node index, plus the root node represents the final evaluation. In order to figure the weight of each evaluation index, it is required that every evaluation node has significant coincident to represent the weight of the evaluation at this node to the one at its parenthood, except for the root node.

Therefore, a system credibility evaluation is transformed into an evaluation network, and it unifies the analysis route of evaluators at a desired leve1 [26, 27].

Traditionally, credibility evaluation is the estimation and reasoning by SMEs' subjective judgments, with the aid of simulation developers on the reference of specific simulation requirements. The work is often difficult to carry out evaluation activities effectively, and always subjective. Now under the evaluation network, SMEs express the relative credibility values quantitatively of leaf nodes and relatively comparisons of branch nodes in simulation systems by Delphi method. The value given by experts may be classified into three different perspectives, shown in Fig. 3. 


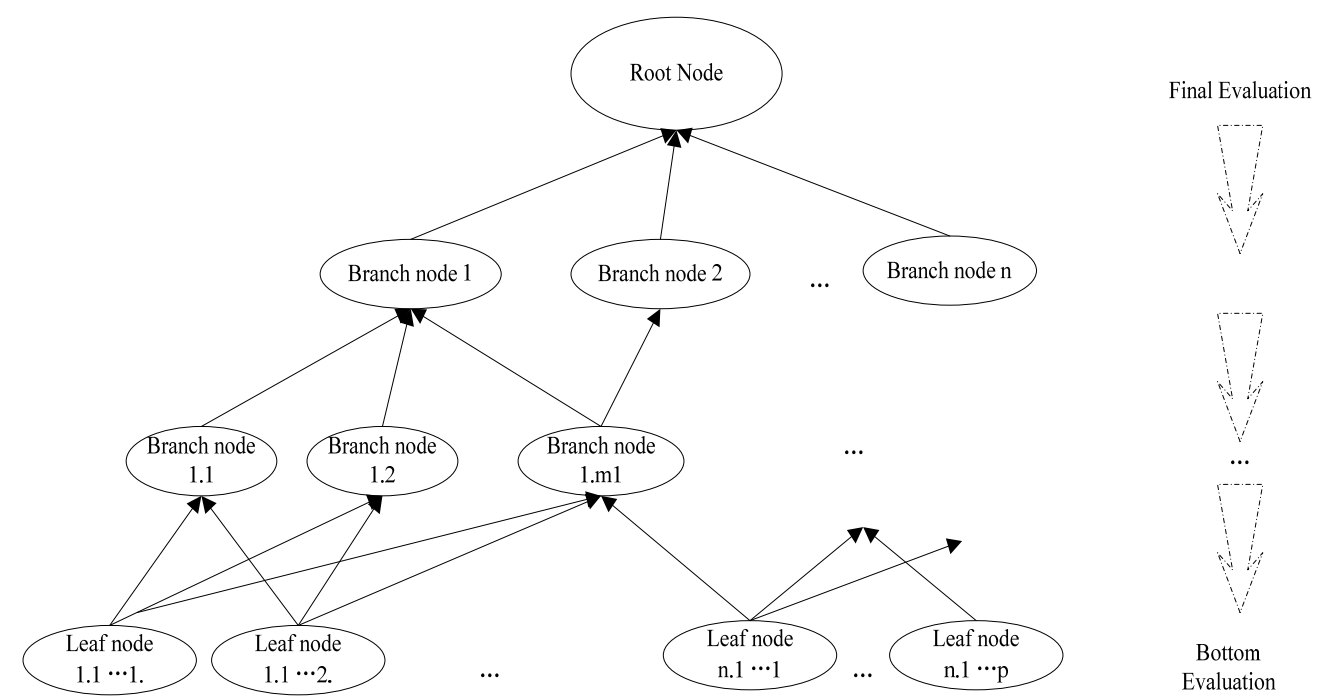

Figure 2: Evaluation network based on V\&V network evaluation.

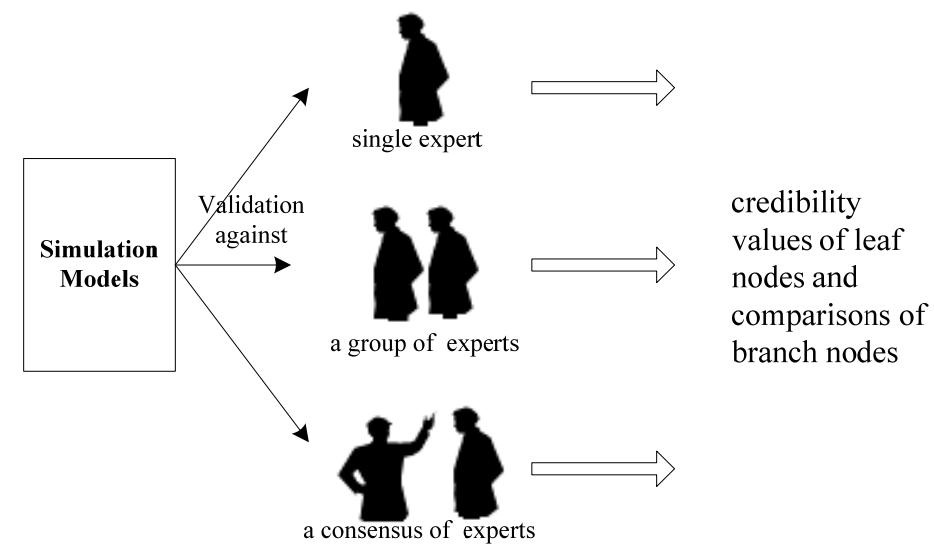

Figure 3: Validation against experts.

Validation against a single expert is simple, but the objectivity of this assessment is questionable. Validation against a group of experts is used to measure the agreements within the group, based on the agreements of each of the pairs of experts in the group. Comparing to its single expert counterpart, the objectivity of evaluation is improved, and the degree of consistency would be gotten between experts. But it's hard to get an evaluation result if the consistency between the experts is low. Validation against a consensus of experts is used to measure the agreement between the consensus of human experts and the simulation models.

Through multiplying the relative credibility values quantitatively of leaf nodes and their corresponding weight values obtained by MFANP, the reasonable final credibility evaluation of the simulation system would get.

\section{EMPIRICAL ILLUSTRATION OF CONTROL\&GUIDE SIMULATION SYSTEM}

An example of a network structure for a complex, multidisciplinary system was an air-breathing, hypersonic cruise missile. The missile is assumed to have an autonomous guidance, navigation, and control (GNC) system, an on-board optical target seeker, and a warhead. Fig. 4 shows the system-level network validation structure for a hypersonic cruise missile [20]. 


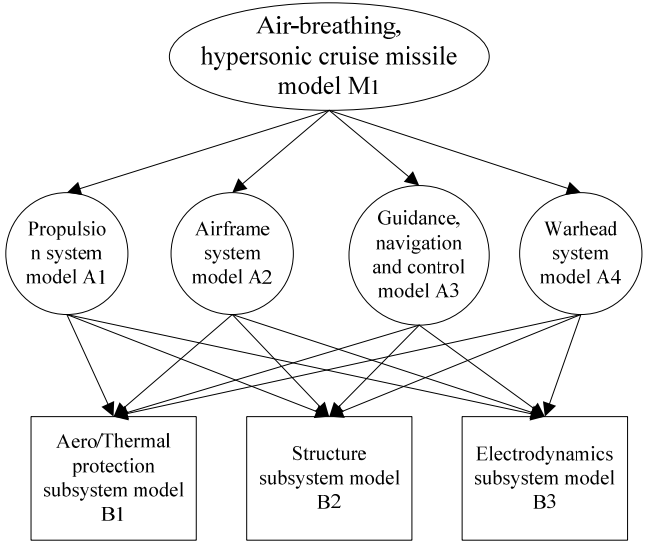

Figure 4: Credibility network of a missile simulation system

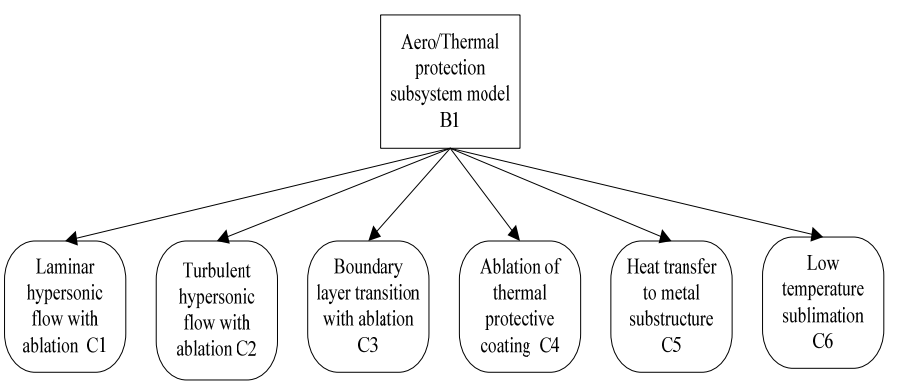

Figure 5: Credibility indices of aero/thermal protection subsystem.

In addition, the structure shown in Fig. 5 focuses on the aero/thermal protection subsystem, for the purpose of analyzing the aero/thermal performance of the missile, as a detail example of credibility evaluation in the leaf-nodes.

\subsection{Credibility calculation for subsystem models}

In the subsystem models, credibility evaluation could divide into leaf-node of hierarchy structure, and we use the proposed method to calculate the indices' weights in aero/thermal protection subsystem model B1 below as a detail example. According to SMEs' the decision, we could get the judgment matrix as follows in Table II. Under the confidence level $\alpha$, we rewrite the judgment matrix as follows in Table III.

Table II: Judgment matrix for kinematical models.

\begin{tabular}{|l|l|l|l|l|l|l|}
\hline & \multicolumn{1}{|c|}{ C1 } & \multicolumn{1}{c|}{ C2 } & \multicolumn{1}{c|}{ C3 } & \multicolumn{1}{c|}{ C4 } & \multicolumn{1}{c|}{ C5 } & \multicolumn{1}{c|}{ C6 } \\
\hline C1 & 1 & $(1 / 3,1 / 2,1)$ & $(1 / 4,1 / 3,1 / 2)$ & $(1,2,3)$ & 1 & 1 \\
\hline C2 & $(1,2,3)$ & 1 & $(1 / 3,1 / 2,1)$ & $(2,3,4)$ & $(1,2,3)$ & $(2,3,4)$ \\
\hline C3 & $(2,3,4)$ & $(1,2,3)$ & 1 & $(4,5,6)$ & $(3,4,5)$ & $(3,4,5)$ \\
\hline C4 & $(1 / 3,1 / 2,1)$ & $(1 / 4,1 / 3,1 / 2)$ & $(1 / 6,1 / 5,1 / 4)$ & 1 & $(1 / 6,1 / 4,1 / 2)$ & 1 \\
\hline C5 & 1 & $(1 / 3,1 / 2,1)$ & $(1 / 5,1 / 4,1 / 3)$ & $(2,4,6)$ & 1 & $(1,3,5)$ \\
\hline C6 & 1 & $(1 / 4,1 / 3,1 / 2)$ & $(1 / 5,1 / 4,1 / 3)$ & 1 & $(1 / 5,1 / 3,1)$ & 1 \\
\hline
\end{tabular}

Table III: Judgment matrix for kinematical models under the confidence level $\alpha$.

\begin{tabular}{|l|l|l|l|l|l|l|}
\hline & \multicolumn{1}{|c|}{ C1 } & \multicolumn{1}{|c|}{ C2 } & C3 & C4 & C5 & C6 \\
\hline C1 & 1 & $\left(\frac{1}{3-\alpha}, \frac{1}{2}, \frac{1}{1+\alpha}\right)$ & $\left(\frac{1}{4-\alpha}, \frac{1}{3}, \frac{1}{2+\alpha}\right)$ & $(1+\alpha, 2,3-\alpha)$ & 1 & 1 \\
\hline C2 & $(1+\alpha, 2,3-\alpha)$ & 1 & $\left(\frac{1}{3-\alpha}, \frac{1}{2}, \frac{1}{1+\alpha}\right)$ & $(2+\alpha, 3,4-\alpha)$ & $(1+\alpha, 2,3-\alpha)$ & $(2+\alpha, 3,4-\alpha)$ \\
\hline C3 & $(2+\alpha, 3,4-\alpha)$ & $(1+\alpha, 2,3-\alpha)$ & 1 & $(4+\alpha, 5,6-\alpha)$ & $(3+\alpha, 4,5-\alpha)$ & $(3+\alpha, 4,5-\alpha)$ \\
\hline C4 & $\left(\frac{1}{3-\alpha}, \frac{1}{2}, \frac{1}{1+\alpha}\right)$ & $\left(\frac{1}{4-\alpha}, \frac{1}{3}, \frac{1}{2+\alpha}\right)$ & $\left(\frac{1}{6-\alpha}, \frac{1}{5}, \frac{1}{4+\alpha}\right)$ & 1 & $\left(\frac{1}{6-2 \alpha}, \frac{1}{4}, \frac{1}{2+2 \alpha}\right)$ & 1 \\
\hline C5 & 1 & $\left(\frac{1}{3-\alpha}, \frac{1}{2}, \frac{1}{1+\alpha}\right)$ & $\left(\frac{1}{5-\alpha}, \frac{1}{4}, \frac{1}{3+\alpha}\right)$ & $(2+2 \alpha, 4,6-2 \alpha)$ & 1 & $(1+2 \alpha, 3,5-2 \alpha)$ \\
\hline C6 & 1 & $\left(\frac{1}{4-\alpha}, \frac{1}{3}, \frac{1}{2+\alpha}\right)$ & $\left(\frac{1}{5-\alpha}, \frac{1}{4}, \frac{1}{3+\alpha}\right)$ & 1 & $\left(\frac{1}{5-2 \alpha}, \frac{1}{3}, \frac{1}{1+2 \alpha}\right)$ & 1 \\
\hline
\end{tabular}

Let $\alpha=0.5$, then we get $C_{1}=(5.186,5.833,6.567) \div(45.53,52.28,61.49)=(0.0843,0.111$, $0.144), C_{2}=(0.153,0.220,0.300), C_{3}=(0.268,0.363,0.472), C_{4}=(0.0499,0.0628,0.0796)$, $C_{5}=(0.124,0.186,0.262), C_{6}=(0.0611,0.0749,0.0919)$. Furthermore, we calculate the 
possibility the fuzzy numbers. $P\left(C_{1} \geq C_{j}\right)=(0.5+0+0+1+0.073+1) / 6=0.43, \quad P\left(C_{2} \geq C_{j}\right)=$ $(1+0.5+0.065+1+0.66+1) / 6=0.7$, Similarity, $P\left(C_{3} \geq C_{j}\right)=0.91, P\left(C_{4} \geq C_{j}\right)=0.125, P\left(C_{5} \geq C_{j}\right)=$ $0.63, P\left(C_{6} \geq C_{j}\right)=0.21$. Then we could gain the weight vector of $C_{i}(i=1, \cdots, 6)$ after normalization, $W_{1}=(0.14,0.23,0.30,0.04,0.21,0.07)$.

SMEs express the relative credibility values quantitatively of leaf nodes in simulation system, indicating the degree achieves the actual effect, as seen in Table IV. After assessing the credibility values of the end values, together with their corresponding total order weight vectors calculated above, we can easily derive the credibility evaluation $E\left(B_{1}\right)$ of the simulation system. The credibility of aero/thermal protection subsystem $B_{1}$ at the given credibility values of leaf-nodes is 0.89 .

Table IV: Given credibility values of kinematical models’ sub-indexes.

\begin{tabular}{|l|c|c|c|c|c|c|}
\hline Sub-indexes & $C_{1}$ & $C_{2}$ & $C_{3}$ & $C_{4}$ & $C_{5}$ & $C_{6}$ \\
\hline Credibility & 0.95 & 0.90 & 0.94 & 0.92 & 0.85 & 0.82 \\
\hline
\end{tabular}

On the analogy the credibility of aero/thermal protection subsystem, other models' credibility values could be calculated under their own leaf-node credibility values.

\subsection{Weight calculation for the network model}

After we get credibility values of subsystem models, we calculate the weight of each subsystem model in the network. The first step below is to compare the importance between each criterion.

Table V: The importance comparisons between $B_{j}$ under $A_{1}$.

\begin{tabular}{|c|c|c|c|c|}
\hline $\mathrm{A}_{1}$ & $\mathrm{~B}_{1}$ & $\mathrm{~B}_{2}$ & $\mathrm{~B}_{3}$ & Normalization $(\alpha=0.5)$ \\
\hline $\mathrm{B}_{1}$ & 1 & $(2,3,4)$ & $(3,4,5)$ & 0.56 \\
\hline $\mathrm{B}_{2}$ & $(1 / 4,1 / 3,1 / 2)$ & 1 & 1 & 0.23 \\
\hline $\mathrm{B}_{3}$ & $(1 / 5,1 / 4,1 / 3)$ & 1 & 1 & 0.21 \\
\hline
\end{tabular}

Table VI: The importance comparisons between $A_{i}$ under $B_{1}$.

\begin{tabular}{|c|c|c|c|c|c|}
\hline $\mathrm{B}_{1}$ & $\mathrm{~A}_{1}$ & $\mathrm{~A}_{2}$ & $\mathrm{~A}_{3}$ & $\mathrm{~A}_{4}$ & Normalization $(\alpha=0.5)$ \\
\hline $\mathrm{A}_{1}$ & 1 & 1 & $(1,2,3)$ & $(1,2,3)$ & 0.375 \\
\hline $\mathrm{A}_{2}$ & 1 & 1 & $(1,2,3)$ & $(1,2,3)$ & 0.375 \\
\hline $\mathrm{A}_{3}$ & $(1 / 3,1 / 2,1)$ & $(1 / 3,1 / 2,1)$ & 1 & 1 & 0.125 \\
\hline $\mathrm{A}_{4}$ & $(1 / 3,1 / 2,1)$ & $(1 / 3,1 / 2,1)$ & 1 & 1 & 0.125 \\
\hline
\end{tabular}

On the analogy of Table V and Table VI, the importance comparisons could be calculated, then comes the supermatrix and the weighted supermatrix as follows:

\begin{tabular}{|c|c|c|c|c|c|c|c|c|c|c|c|c|c|c|c|}
\hline & $A_{1}$ & $A_{1}$ & $A_{3}$ & $A_{4}$ & $B_{1}$ & $B_{2}$ & $B_{3}$ & & $A_{1}$ & $A_{1}$ & $A_{3}$ & $A_{4}$ & $B_{1}$ & $B_{2}$ & $B_{3}$ \\
\hline$A_{1}$ & 1 & & & & 0.375 & 0.4 & 0.25 & $A_{1}$ & 0.5 & & & & 0.1875 & 0.2 & 0.125 \\
\hline$A_{2}$ & & 1 & & & 0.375 & 0.2 & 0.25 & $A_{2}$ & & 0.5 & & & 0.1875 & 0.1 & 0.125 \\
\hline$A_{3}$ & & & 1 & & 0.125 & 0.2 & 0.3 & $A_{3}$ & & & 0.5 & & 0.0625 & 0.1 & 0.15 \\
\hline$A_{4}$ & & & & 1 & 0.125 & 0.2 & 0.2 & $A_{4}$ & & & & 0.5 & 0.0625 & 0.1 & 0.1 \\
\hline$B_{1}$ & 0.56 & 0.58 & 0.64 & 0.14 & 1 & & & $B_{1}$ & 0.28 & 0.29 & 0.32 & 0.07 & 0.5 & & \\
\hline$B_{2}$ & 0.23 & 0.11 & 0.11 & 0.65 & & 1 & & $B_{2}$ & 0.115 & 0.055 & 0.05 & 0.325 & & 0.5 & \\
\hline$B_{3}$ & 0.21 & 0.31 & 0.26 & 0.21 & & & 1 & $B_{3}$ & 0.105 & 0.155 & 0.13 & 0.105 & & & 0.5 \\
\hline
\end{tabular}


The final limit supermatrix is:

$\left.\begin{array}{c|ccccccc}\multicolumn{2}{c}{A_{1}} & A_{1} & A_{3} & A_{4} & B_{1} & B_{2} & B_{3} \\ A_{1} & 0.175 & 0.175 & 0.175 & 0.175 & 0.175 & 0.175 & 0.175 \\ A_{2} & 0.151 & 0.151 & 0.151 & 0.151 & 0.151 & 0.151 & 0.151 \\ A_{3} & 0.093 & 0.093 & 0.093 & 0.093 & 0.093 & 0.093 & 0.093 \\ A_{4} & 0.081 & 0.081 & 0.081 & 0.081 & 0.081 & 0.081 & 0.081 \\ B_{1} & 0.257 & 0.257 & 0.257 & 0.257 & 0.257 & 0.257 & 0.257 \\ B_{2} & 0.119 & 0.119 & 0.119 & 0.119 & 0.119 & 0.119 & 0.119 \\ B_{3} & 0.125 & 0.125 & 0.125 & 0.125 & 0.125 & 0.125 & 0.125\end{array}\right)$

The final limit supermatrix expresses the weight of $A_{i}$ and $B_{j}(i=1, \cdots, 4, j=1, \cdots, 3)$ in the network structure of the complex air-breathing, hypersonic cruise missile model. After weighted average synthesis with the credibility values of subsystem models in the section above, the final result of the missile model's credibility value could receive.

The air-breathing, hypersonic cruise missile simulation system can be described as a system of multi-component that forms a network, where every component can interact or have an influence on itself or some or all of the other components of the system. The credibility of the simulation system could be calculated through the proposed modified ANP method.

There are many kinds of methods in simulation credibility evaluation, but before this method is proposed forward, credibility evaluation for complex simulation systems involving network configurations, is a tough task. What's more, uncertainty degree of understanding in pairwise comparisons is also rarely considered, in the previous researches. The MFANP method gives a reasonable and feasible approach for these problems.

\section{CONCLUSIONS}

In this paper, we propose a modified fuzzy ANP approach and its application in credibility study of simulation systems. The complexity of simulation applications brings much difficulties in credibility evaluation based on hierarchy structure using AHP method. Corresponding, ANP could deal with compound network structure involving components interact with others. ANP has been widely used in evaluating various kinds of decision problems in both academic researches and practices. Due to the vagueness and uncertainty on judgments of the decision-maker(s), the crisp pair wise comparison in the conventional ANP seems to insufficient and imprecise to capture the right judgments. That is why; the modified fuzzy ANP approach is introduced. The improved method takes into account the $\alpha$-cuts level, which could achieve a more accurate conclusion, particularly the quality of a fuzzy number being considered in the index. Besides the confidence level, MFANP proposes more reasonable method to calculate the weight vectors by possibility of TFNs.

The approach is used in simulation system to assess the credibility of the process for the credibility evaluation, and what's more, this may be a new approach and new ideas for the later evaluation of complex simulations, due to the similarity of network framework in M\&S V\&V studies.

There are also some deficiencies, such as the credibility values of decomposed sub-nodes need to be given by experts' subjective experience, and the objectivity of the credibility values need to be investigated in the further works. The proposed method may be applied in other alternative evaluation problems. This needs to evaluate the suitability of each credibility problem, because each simulation system has its own unique characteristic. However, it could lead to lots of calculations to reach the final solution as the number of criteria and alternatives increases considerably. As a result, development of an expert system or software prototype 
based on the method is useful to overcome this problem. Besides the fuzzy property caused by vagueness and uncertainty, some model may have probable property, and how to integrate ANP with other uncertain methods, such as fuzzy cognitive map, Bayesian inference, Dempster-Shafer evidence theory, is still open-air.

\section{ACKNOWLEDGEMENTS}

The authors would like to thank the anonymous reviewers for many constructive comments that helped to improve an earlier version of this paper. The authors would also like to thank the support of the Foundation of the Outstanding Youth of Heilongjiang Province, China (Grant No. JC200606).

\section{REFERENCES}

[1] Saaty, T. L. (1981). The Analytic Hierarchy Process, McGraw- Hill, New York

[2] Saaty, T. L. (2004). Decision making: the Analytic Hierarchy and Network Process (AHP/ANP), Journal of Systems Science and Systems Engineering, Vol. 13, No. 1, 1-35

[3] Saaty, T. L. (2005). Making and validating complex decisions with the AHP/ANP, Journal of Systems Science and Systems Engineering, Vol. 14, No. 1, 1-36

[4] Saaty, T. L. (2007). Time dependent decision-making; dynamic priorities in the AHP/ANP: Generalizing from points to functions and from real to complex variables, Mathematical and Computer Modeling, Vol. 46, 860-891, doi:10.1016/j.mcm.2007.03.028

[5] Van Laarhoven, P. J. M.; Pedrycz, W. (1983). A fuzzy extention of Saaty's priority theory, Fuzzy Sets and Systems, Vol. 11, No. 3, 229-241

[6] Buckley, J. J. (1985). Fuzzy hierarchical analysis, Fuzzy Sets and Systems, Vol. 17, No. 3, 233-247

[7] Chang, D. Y. (1996). Application of the extent analysis method on fuzzy AHP, European Journal of Operational Research, Vol. 95, 649-655

[8] Zhu, K. J.; Yu, J.; Chang, D. Y. (1999). A discussion on Extent Analysis Method and applications of fuzzy AHP, European Journal of Operational Research, Vol. 116, 450-456

[9] Chen, S. M. (1996). Evaluating weapon systems using fuzzy arithmetic operations, Fuzzy Sets and Systems, Vol. 77, 265-276

[10] Chen, L. S.; Cheng, C. H. (2005). Selecting IS personnel use fuzzy GDSS based on metric distance method, European Journal of Operational Research, Vol. 160, 803-820

[11] Yang, C. C.; Chen, B. S. (2004). Key quality performance evaluation using fuzzy AHP, Journal of the Chinese Institute of Industrial Engineers, Vol. 21, No. 6, 543-550

[12] Ayag, Z.; Özdemir, R. G. (2006). A fuzzy AHP approach to evaluating machine tool alternatives, Journal of Intelligent Manufacturing, Vol. 17, 179-190, doi 10.1007/s10845-005-6635-1

[13] Dagdeviren, M.; Yuksel, I; Kurt, M. (2008). A fuzzy analytic network process (ANP) model to identify faulty behavior risk (FBR) in work system, Safety Science, Vol. 46, 771-783, doi:10.1016/j.ssci.2007.02.002

[14] Guneri, A. F.; Cengiz, M.; Seker, S. (2009). A fuzzy ANP approach to shipyard location selection, Expert Systems with Applications, Vol. 36, 7992-7999, doi:10.1016/j.eswa.2008.10.059

[15] Fiala, P. (2006). An ANP/DNP analysis of economic elements in today's world network economy, Journal of Systems Science and Systems Engineering, Vol. 15, No. 2, 131-140, doi: 10.1007/s11518-006-5002-X

[16] Wijnmalen, D. J. D. (2007). Analysis of benefits, opportunities, costs, and risks (BOCR) with the AHP/ANP: A critical validation, Mathematical and Computer Modelling, Vol. 46, 892-905, doi:10.1016/j.mcm.2007.03.020

[17] Chung, S. H.; Lee, A. H. I.; Pearn, W. L. (2005). Analytic network process (ANP) approach for product mix planning in semiconductor fabricator, Int. Journal of Production Economics, Vol. 96, 15-36, doi:10.1016/j.ijpe.2004.02.006 
[18] Agarwal, A; Shankar, R; Tiwari, M. K. (2006). Modeling the metrics of lean, agile and leagile supply chain: An ANP-based approach, European Journal of Operational Research, Vol. 173, 211-225, doi:10.1016/j.ejor.2004.12.005

[19] Yuksel, I.; Dagdeviren, M. (2007). Using the analytic network process (ANP) in a SWOT analysis: A case study for a textile firm, Information Sciences, Vol. 177, 3364-3382, doi:10.1016/j.ins.2007.01.001

[20] Oberkampf, W. L.; Trucano, T. G. (2008). Verification and validation benchmarks, Nuclear Engineering and Design, Vol. 238, 716-743, doi:10.1016/j.nucengdes.2007.02.032

[21] Balic, O. (2004). Quality Assessment, Verification, and Validation of Modeling and Simulation Applications, Proceedings of the 2004 Winter Simulation Conference, 122-129

[22] DMSO (2000). VV\&A Recommended Practices Guide. [DB/OL], www.dmso.mil.

[23] Shi, P.; Liu, F.; Yang, M. (2008). Research on validation method for complex simulation systems, 2008 Asia Simulation Conference, ICSC, 888-892

[24] Liu, F.; Ma, P.; Yang, M.; Wang, Z. C. (2009). Key problems in validation of intelligent models, Journal of Harbin Institute of Technology (New Series), Vol. 16, 371-375

[25] Liu, F.; Yang, M.; Wang, Z. C. (2008), VV\&A Solution for Complex Simulation Systems, International Journal of Simulation, Vol. 9, No. 1, 21-29

[26] Fang, K.; Yang, M.; Wang, Z. C. (2005). A VV\&A evaluation system based on hierarchical evaluation, Journal of Harbin Institute of Technology (New Series), Vol. 12, No. 2, 184-188

[27] Yang, M.; Zhang, B.; Wang, Z. C. (2003). Five Key Issues of the Development of Simulation Systems VV\&A, Journal of System Simulation, Vol. 15, No. 11, 1506-1509 